\title{
Primary versus secondary tracheoesophageal puncture: systematic review and meta-analysis
}

\author{
P D CHAKRAVARTY ${ }^{1}$, A E L MCMURRAN ${ }^{2}$, A BANIGO $^{3}$, M SHAKEEL $^{3}, \mathrm{~K}$ W AH-SEE ${ }^{3}$ \\ ${ }^{1}$ Department of Otolaryngology, Head and Neck Surgery, Queen Elizabeth University Hospital, Glasgow, \\ ${ }^{2}$ Department of Otolaryngology, Ninewells Hospital, Dundee, and ${ }^{3}$ Department of Otolaryngology, Head and Neck \\ Surgery, Aberdeen Royal Infirmary, Scotland, UK
}

\begin{abstract}
Background: Tracheoesophageal puncture represents the 'gold standard' for voice restoration following laryngectomy. Tracheoesophageal puncture can be undertaken primarily during laryngectomy or in a separate secondary procedure. There is no current consensus on which approach is superior. The current evidence comparing primary and secondary tracheoesophageal puncture was assessed.

Methods: A systematic review and meta-analysis of articles comparing outcomes for primary and secondary tracheoesophageal puncture after laryngectomy were conducted. Outcome measures were: voice success, overall complication rate and pharyngocutaneous fistula rate.

Results: Eleven case series met the inclusion criteria, two prospective and nine retrospective. Meta-analysis did not demonstrate statistically significant differences in overall complication rate or voice outcomes, though it suggested a significantly increased risk of pharyngocutaneous fistula in primary compared to secondary tracheoesophageal puncture.

Conclusion: Primary tracheoesophageal puncture is a safe and efficient approach for voice rehabilitation. However, secondary tracheoesophageal puncture should be preferred where there is a higher risk of pharyngocutaneous fistula.
\end{abstract}

Key words: Laryngectomy; Voice Prosthesis; Esophageal Speech

\section{Introduction}

Since Bilroth first described laryngectomy in 1873, several options for post-operative voice restoration have been implemented. The current 'gold standard' in rehabilitation is the use of a voice prosthesis following a tracheoesophageal puncture procedure, popularised by Singer and Blom in the early 1980s. ${ }^{1}$ Benefits of tracheoesophageal puncture over other alaryngeal speech methods include longer phonation time, more syllables per breath and greater maximum intensity level. ${ }^{2}$

More contentious, however, is the timing of the tracheoesophageal puncture. The original description of tracheoesophageal puncture insertion was as a secondary procedure in patients post-laryngectomy, but increasingly it has been performed primarily as part of the laryngectomy. This is conducted with the intention of eliminating a second surgical intervention and to accelerate voice rehabilitation. ${ }^{3}$ However, traditionally, a secondary puncture is preferred for patients at higher risk of complications such as wound breakdown and fistula formation, ${ }^{1}$ as it provides more time for adequate healing of the laryngostoma prior to formation of the tracheoesophageal puncture.

It has been established that both primary and secondary tracheoesophageal puncture techniques are safe in the long term, ${ }^{4}$ with high rates of successful voice rehabilitation. However, there is considerable variation in the voice success rate reported among studies, ${ }^{5,6}$ which typically ranges from 70 to 90 per cent. Differences in surgical experience, technique and preference, population demographics, and follow-up periods make comparisons of studies evaluating the outcomes of primary and secondary tracheoesophageal puncture difficult.

Critically, no consensus has been reached with respect to whether one approach is more efficacious than the other in terms of voice success, or whether one approach results in a more complicated post-operative period. This systematic review and meta-analysis aimed to evaluate the evidence comparing primary and secondary tracheoesophageal puncture, in terms 
of voice outcomes, overall complication rate and complication type, with a view to establishing any differences in patient outcome reflected in the literature.

\section{Materials and methods}

A comprehensive literature search was conducted of databases including Medline, Embase (Ovid), Cumulative Index to Nursing and Allied Health Literature ('CINAHL'; Ebsco collections) and the Cochrane Library. The search terms used were: 'total laryngectomy', 'tracheooesophageal puncture', 'BlomSinger prosthesis', 'esophageal speech', 'laryngectomy', 'alaryngeal speech', 'larynx, artificial' or 'laryngeal prosthesis', and 'voice restoration', 'speech rehabilitation', 'voice prosthesis rehabilitation', 'voice rehabilitation' or 'speech restoration'. The final search was carried out on 3rd February 2016. The primary outcomes of this study were: voice quality/success, overall complication rate and pharyngocutaneous fistula rate. The inclusion and exclusion criteria are shown in Table I.

All studies identified by the initial literature search were reviewed independently by two authors (PDC and AELM). All titles and abstracts were assessed, and when in doubt the full text was scrutinised. Data were independently extracted from papers that met the inclusion criteria by two authors, using a piloted proforma. Any differences in extracted data and study eligibility were discussed, and if a dispute remained this was resolved by a senior author. Extracted data included: study type, sample size, follow-up period, loss to follow up, patient characteristics, complications and voice outcomes. Information regarding other treatment modalities (chemo/radiotherapy, neck dissection and reconstruction) was also collated.

After data collection, the two independent reviewers carried out an assessment of the risk of bias in each study. As all the papers studied were non-randomised, a validated measure of the methodological quality features of non-randomised data, the Downs and Black instrument, ${ }^{7}$ was used.

Review Manager software (RevMan version 5.3, 2014), available from the Cochrane Library, was used

\begin{tabular}{l} 
TABLE I \\
INCLUSION AND EXCLUSION CRITERIA \\
\hline Inclusion criteria \\
- Direct comparison of outcomes of primary \& secondary \\
tracheoesophageal puncture after laryngectomy \\
- Published in English language \\
Exclusion criteria \\
- Articles including patients undergoing partial or total \\
glossectomy \\
- Published before 1980 \\
- Studies evaluating tracheoesophageal puncture in other contexts \\
\hline Blom and Singer described the first tracheoesophageal puncture \\
in 1980. Given the impact on voice outcomes, articles evaluating \\
partial or total glossectomy were excluded. No exclusions were \\
made on the basis of study design alone.
\end{tabular}

to analyse data collected from the included studies, to produce statistical outcomes and figures.

\section{Results}

\section{Literature search}

An initial key word search of the listed databases yielded 902 articles in total. After de-duplication and assessment of relevance, 867 articles were excluded. Thirty-five articles were deemed to be relevant. Eleven of these studies, with a total of 937 subjects, met the inclusion and exclusion criteria, and were analysed, as shown in Figure 1.

\section{Study characteristics and quality}

The 11 articles included were all case series in design; 2 were prospective $e^{8,9}$ and 9 were retrospective. ${ }^{10-18}$ The articles were published across a period of 30 years (1985-2015). Sample size ranged from 23 to 145 patients in total. Timing of secondary tracheoesophageal puncture ranged both within and between studies, from one month to over three years. There was a significant male preponderance ( 83.8 per cent) among the participants included in this analysis. Baseline characteristics are shown in Table II.

Data were collected on a range of confounding factors, and reporting of these was variable, as shown in Table III. Every study, except that by Moon et al., ${ }^{14}$ reported the total number of patients who underwent chemo/radiotherapy either pre-operatively or post-operatively, but there was variable reporting of the proportion of patients in each group undergoing these treatments. Five of the 11 studies reported did not specify if patients underwent neck dissection at the same time as laryngectomy, and 3 studies did not specify whether there was any concurrent surgical reconstruction.

The articles included provided level 4 evidence ${ }^{19}$ and were of generally poor methodological quality. There was no randomisation or blinding, nor any significant effort to eliminate allocation bias across the studies. The mean Downs and Black score was 18.25 (range, 11-22), as shown in Table II.

Follow-up duration ranged from one month to three years, and there was up to 23 per cent loss to follow up across the studies.

\section{Voice outcomes}

All the studies included compared voice success/ quality between the two groups; however, the definitions used to compare success were very different. Similarly, a range of groups undertook assessment of voice outcome, including speech and language therapists, surgeons, and lay people. Table IV shows the methods of assessment employed.

Three studies employed a cut-off score using a voice rating scale to determine successful voice rehabilitation. Other methods of determining success were: use of a voice prosthesis as main means of communication, 


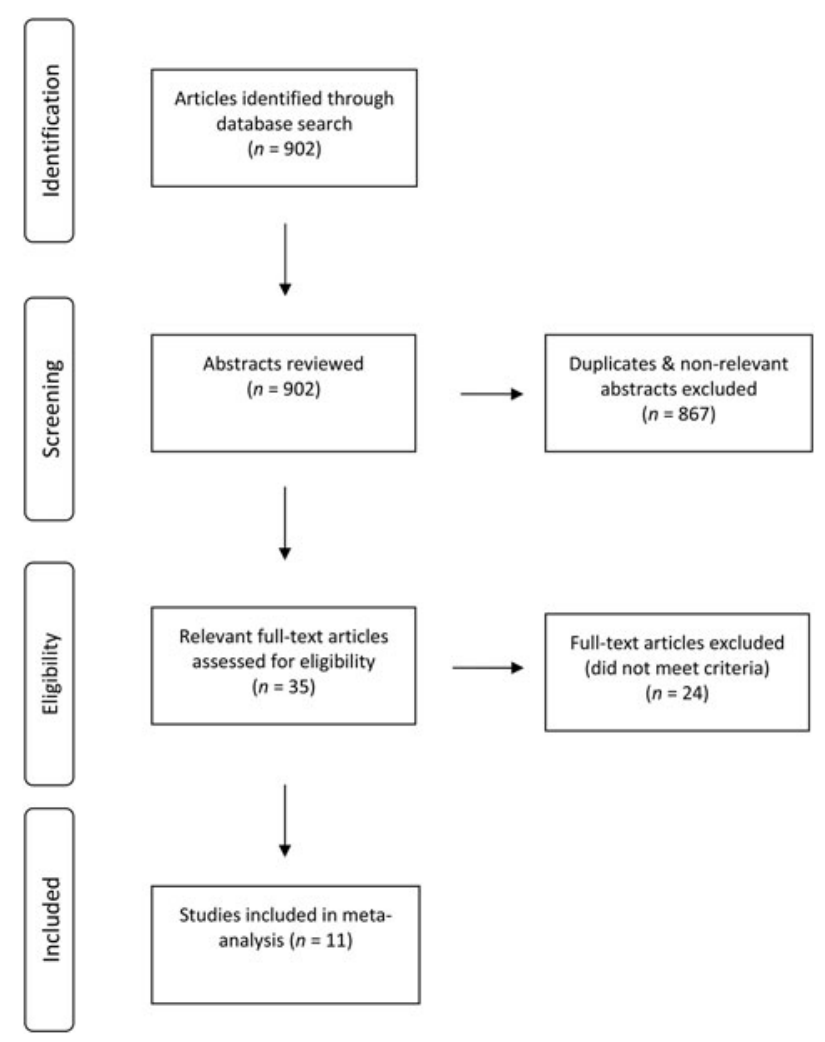

FIG. 1

Flow chart showing literature search strategy.

and 'excellent', 'good' or 'intelligible' use of voice post-operatively. The percentages of patients reaching these standards were compared, some in the immediate post-operative period and others at one year and beyond. None of the studies analysed demonstrated a significant difference in voice outcomes between primary and secondary tracheoesophageal puncture individually.

A meta-analysis was undertaken, which showed a trend favouring better voice outcomes with primary tracheoesophageal puncture, but there was no significant difference in voice success between the two groups (odds ratio $=0.81$ (95 per cent confidence interval (CI), 0.50-1.30); Figure 2).

\section{Complications}

Data were collected with respect to the total complications in all studies. Only surgical complications were included, with pharyngocutaneous fistula included within the overall complication rate analysis. Other typical complications were: wound infection, bleeding, fistula migration and stomal stenosis. Again, none of the studies independently found any significant difference in overall complication rate between patients

\begin{tabular}{|c|c|c|c|c|c|c|c|}
\hline & BASELI & $\begin{array}{r}\text { TABL } \\
\text { CHARACTERISTIC }\end{array}$ & ND QUAL & TY FEAT & & & \\
\hline Study (year) & $\begin{array}{l}\text { Sample } \\
\text { size }(n)\end{array}$ & $\begin{array}{l}\text { Primary/secondary } \\
\text { tracheoesophageal } \\
\text { puncture }(n)\end{array}$ & $\begin{array}{l}\text { Male-to- } \\
\text { female } \\
\text { ratio }\end{array}$ & $\begin{array}{l}\text { Mean } \\
\text { age } \\
\text { (years) }\end{array}$ & $\begin{array}{l}\text { Mean } \\
\text { minimum } \\
\text { follow up } \\
\text { (months) }\end{array}$ & $\begin{array}{l}\text { Loss to } \\
\text { follow up } \\
\qquad(n)\end{array}$ & $\begin{array}{c}\text { Mean } \\
\text { Downs \& } \\
\text { Black } \\
\text { score }\end{array}$ \\
\hline Morrison \& O'Grady ${ }^{15}$ (1986) & 26 & $13 / 13$ & 20:6 & 60 & 2 & NS & 20 \\
\hline Maniglia et al. ${ }^{8}$ (1989) & 95 & $33 / 62$ & $76: 19$ & 61 & 12 & 0 & 17 \\
\hline Wenig et al. ${ }^{18}$ (1989) & 38 & $20 / 18$ & $25: 13$ & 59 & 24 & 1 & 20 \\
\hline Geraghty et al. ${ }^{13}$ (1996) & 40 & $18 / 22$ & $30: 10$ & 56 & 36 & 13 & 15 \\
\hline Shenoy et al..$^{17}(2000)$ & 23 & $15 / 8$ & $21: 2$ & 54 & 1 & 0 & 11 \\
\hline Cheng et al. ${ }^{12}$ (2006) & 68 & $51 / 17$ & $54: 14$ & 58 & NS & 0 & 22 \\
\hline Boscolo-Rizzo et al. ${ }^{10}$ (2008) & 93 & $75 / 18$ & $87: 6$ & 62 & 24 & 9 & 20 \\
\hline Bozec et al. ${ }^{11}$ (2010) & 87 & $79 / 8$ & NS & 65 & 6 & 5 & 21 \\
\hline 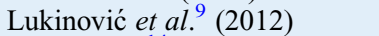 & 91 & $20 / 71$ & $88: 3$ & 64 & 2 & 9 & 19 \\
\hline Moon et al. ${ }^{14}(2014)$ & 145 & $70 / 75$ & NS & 65 & 12 & NS & 18 \\
\hline Serra et al. ${ }^{16}(2015)$ & 95 & $43 / 52$ & $78: 17$ & 61 & 12 & NS & 18 \\
\hline
\end{tabular}




\begin{tabular}{|c|c|c|c|c|}
\hline \multicolumn{5}{|c|}{$\begin{array}{c}\text { TABLE III } \\
\text { MAJOR CONFOUNDING FACTORS }\end{array}$} \\
\hline Study (year) & Sample size $(n)$ & Chemo/radiotherapy $(n)$ & Neck dissection $(n)$ & Reconstruction $(n)$ \\
\hline Morrison \& O'Grady ${ }^{15}$ (1986) & 26 & 25 & 5 & 2 \\
\hline Maniglia et al. ${ }^{8}(1989)$ & 95 & 69 & 33 & 0 \\
\hline Wenig et al. ${ }^{18}(1989)$ & 38 & 20 & 16 & 14 \\
\hline Geraghty et al. ${ }^{13}$ (1996) & 40 & NS & NS & NS \\
\hline Shenoy et al. ${ }^{17}(2000)$ & 23 & 22 & NS & NS \\
\hline Cheng et al. ${ }^{\text {i2 }}$ (2006) & 68 & 49 & NS & 15 \\
\hline Boscolo-Rizzo et al. ${ }^{10}$ (2008) & 93 & 47 & NS & NS \\
\hline Bozec et al. ${ }^{11}(2010)$ & 87 & 70 & 64 & 45 \\
\hline Lukinović et al. ${ }^{9}(2012)$ & 91 & 73 & NS & NS \\
\hline Moon et al..$^{14}$ (2014) & 145 & 93 & NS & 45 \\
\hline Serra et al. $^{16}$ (2015) & 95 & 17 & 10 & 18 \\
\hline
\end{tabular}

$\mathrm{NS}=$ not specified

undergoing primary and secondary puncture (Table V). Meta-analysis revealed trends towards a generally higher overall complication rate in the primary procedure group, but the difference was not significant (odds ratio $=1.46$ (95 per cent CI, 1.00-2.11)), as shown in Figure 3.

\section{Pharyngocutaneous fistulae}

Five of 11 studies recorded pharyngocutaneous fistula as an individual complication among their analysed population. Generally speaking, these were more prevalent in the studies performed in the 1980s. When reported as a complication, it was quite common, occurring in more than 15 per cent of punctures. None of the studies had statistically compared the rate of fistulae between the two groups. Meta-analysis suggested that pharyngocutaneous fistulae are significantly more common following primary tracheoesophageal puncture (odds ratio $=1.99(95$ per cent $\mathrm{CI}$, 1.07-3.70); Figure 4). Table VI compares the characteristics of the five studies that compared pharyngocutaneous fistula between patients who underwent primary or secondary punctures.

\section{Discussion}

This systematic review and meta-analysis suggests that the outcomes of primary and secondary tracheoesophageal puncture are quite similar. Timing of the tracheoesophageal puncture did not significantly affect voice outcomes, though the trend favours greater voice success with a primary puncture. There was no difference in overall complication rate; however, meta-analysis of the five studies that reported pharyngocutaneous fistula

\begin{tabular}{|c|c|c|c|c|}
\hline \multicolumn{5}{|c|}{$\begin{array}{l}\text { TABLE IV } \\
\text { D COMPARISON OF VOICE SUCCESS }\end{array}$} \\
\hline Study (year) & $\begin{array}{l}\text { Primary or secondary } \\
\text { tracheoesophageal } \\
\text { puncture }\end{array}$ & Voice success assessment & Success $(\%)$ & $P$-value* \\
\hline Morrison \& O'Grady ${ }^{15}$ (1986) & Primary & 'Excellent' or 'good' rating by surgical team & 76.9 & \\
\hline & Secondary & & 53.8 & \\
\hline Maniglia et al. ${ }^{8}(1989)$ & Primary & Success at 12 months & 84.8 & $<0.077$ \\
\hline Wenig et al. ${ }^{18}$ (1989) & $\begin{array}{l}\text { Secondary } \\
\text { Primary }\end{array}$ & 'Excellent' or 'good' rating by SALT \& layperson & 57.9 & \\
\hline Geraghty et al. ${ }^{13}$ (1996) & $\begin{array}{l}\text { Secondary } \\
\text { Primary } \\
\text { Secondary }\end{array}$ & Initial voice success & $\begin{array}{l}61.1 \\
66.7 \\
72.7\end{array}$ & \\
\hline Shenoy et al. ${ }^{17}(2000)$ & $\begin{array}{l}\text { Primary } \\
\text { Secondary }\end{array}$ & Initial voice success & $\begin{array}{l}93.3 \\
62.5\end{array}$ & \\
\hline Cheng et al. ${ }^{12}$ (2006) & $\begin{array}{l}\text { Primary } \\
\text { Secondary }\end{array}$ & 'Excellent' rating by SALT & $\begin{array}{l}78.4 \\
70.6\end{array}$ & \\
\hline Boscolo-Rizzo et al. ${ }^{10}$ (2008) & $\begin{array}{l}\text { Primary } \\
\text { Secondary }\end{array}$ & HRS score $>11$ & $\begin{array}{l}80 \\
88.9\end{array}$ & 0.596 \\
\hline Bozec et al. ${ }^{11}(2010)$ & $\begin{array}{l}\text { Primary } \\
\text { Secondary }\end{array}$ & Intelligible voice rated by SALT & $\begin{array}{l}81 \\
87.5\end{array}$ & \\
\hline Lukinović et al. ${ }^{9}$ (2012) & $\begin{array}{l}\text { Primary } \\
\text { Secondary }\end{array}$ & Hilger score $>3$ & $\begin{array}{l}90 \\
71.8\end{array}$ & 0.078 \\
\hline Moon et al. ${ }^{14}$ (2014) & $\begin{array}{l}\text { Primary } \\
\text { Secondary }\end{array}$ & Use of tracheoesophageal puncture for speech & $\begin{array}{l}76 \\
68\end{array}$ & 0.3 \\
\hline Serra et al. ${ }^{16}(2015)$ & $\begin{array}{l}\text { Primary } \\
\text { Secondary }\end{array}$ & HRS score $>11$ & $\begin{array}{l}84 \\
91\end{array}$ & 0.613 \\
\hline
\end{tabular}

${ }^{*} P$-values presented when available. SALT $=$ speech and language therapist; HRS $=$ Harrison-Robillard-Schultz tracheoesophageal puncture rating scale 


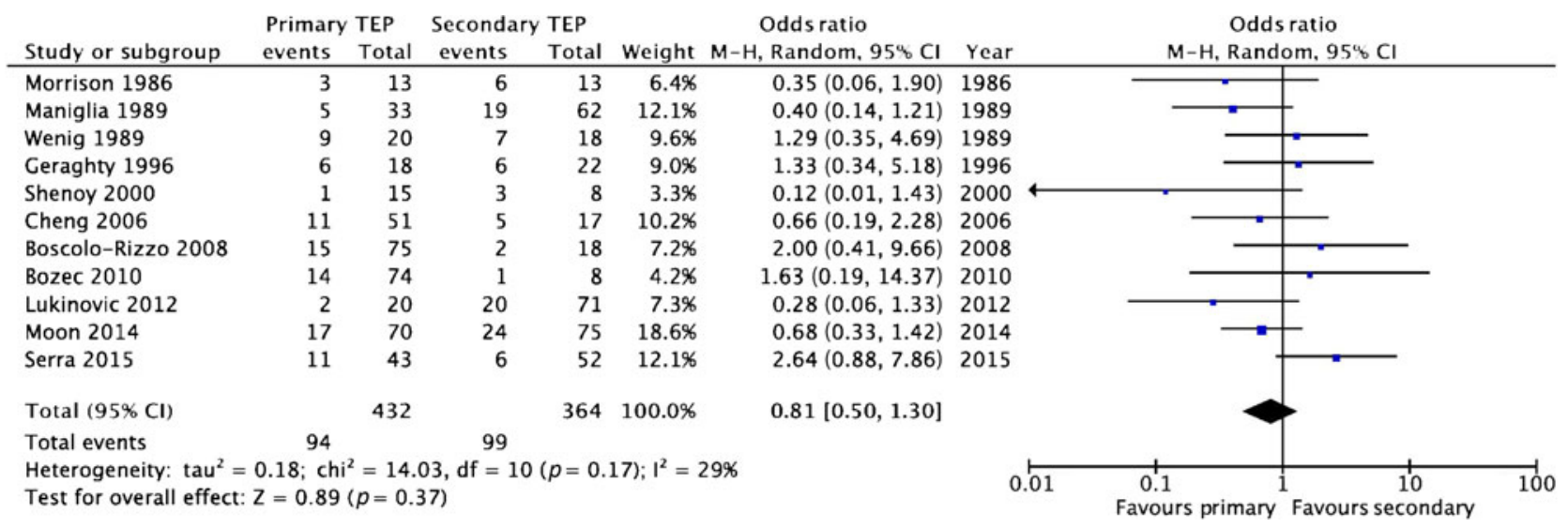

FIG. 2

Forest plot showing meta-analysis of voice outcomes. Percentages of patients with voice failure following primary and secondary tracheoesophageal puncture ('TEP') are compared. Voice failure was more prevalent after secondary puncture, though this difference is not significant. $\mathrm{M}-\mathrm{H}=$ Mantel-Haenszel value; $\mathrm{CI}=$ confidence interval

as an outcome found it to be significantly more prevalent following primary punctures.

To our knowledge, this will be the first published meta-analysis comparing the outcomes of primary and secondary tracheoesophageal puncture. A robust literature search strategy was employed, which yielded a sufficient number of studies that directly compared the two interventions to undertake a systematic review and meaningful evaluation. Primary outcomes and study design were similar throughout the included studies, and the data yielded were homogeneous enough to allow for statistical analysis. Baseline characteristics were generally similar. The studies included spanned 30 years and encompass the entire history of the technique.
There were, however, several shortcomings to this study. Baseline characteristics were reported poorly in most cases; only age was reported universally. It was not possible to determine gender distribution in 2 studies, ${ }^{11,14}$ and only 4 of 11 studies reported the stage of the primary cancer. The overall quality of the data was poor, with studies only providing level 4 data across the board. The reliability of the results is hampered by generally small sample sizes, missing data and variable follow up. No steps were taken to eliminate selection bias among both the retrospective and prospective case series. As mentioned previously, voice outcomes were reported very differently in these studies, and the only measurement tool used consistently was voice success/failure. We were unable to

\begin{tabular}{lccc}
\multicolumn{3}{c}{ TABLE V } & \\
OVERALL COMPLICATION RATE AND PHARYNGOCUTANEOUS FISTULA INCIDENCE
\end{tabular}

${ }^{*} P$-values presented when available. 


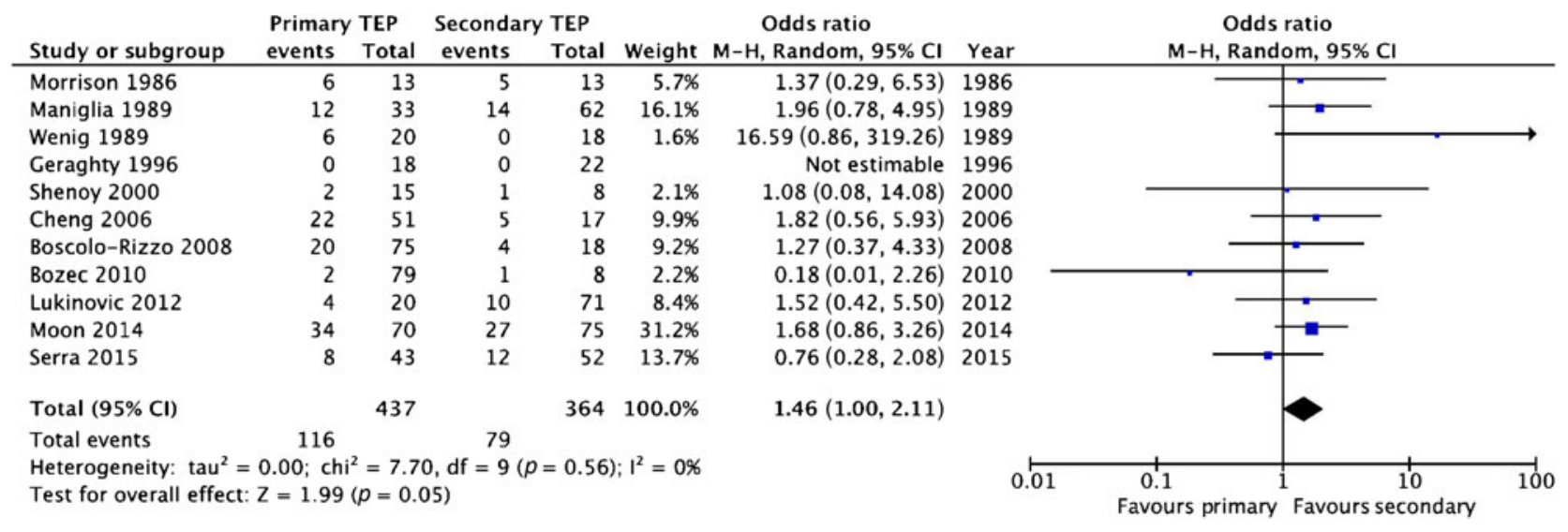

FIG. 3

Forest plot showing meta-analysis of overall complication rates after primary and secondary puncture. The trend suggests the overall complication rate may be lower with secondary puncture, though this was of borderline significance. TEP $=$ tracheoesophageal puncture; $\mathrm{M}-\mathrm{H}=$ Mantel-Haenszel value; $\mathrm{CI}=$ confidence interval

comment on time to voice or voice quality based on the studies included.

The significant finding that pharyngocutaneous fistula seems to be associated with primary tracheoesophageal puncture is limited by the fact that only 5 of 11 studies report this as a complication, despite this being a common issue affecting 10-34 per cent of patients after laryngectomy. ${ }^{20}$ This may be because the articles included focused on voice outcome, a factor not typically affected by pharyngocutaneous fistula.

In terms of confounding factors, we sought to reduce operative heterogeneity by excluding articles comprising patients who underwent partial or total glossectomy, on the basis of effects on voice outcomes. ${ }^{21}$ However, five articles ${ }^{10,11,15,16,18}$ included patients who underwent circular or non-circular pharyngolaryngectomy (6.4-36 per cent of participants). The distribution of these patients within primary and secondary tracheoesophageal puncture groups was not described in four instances. Serra et al. performed secondary tracheoesophageal puncture on all patients with pharyngolaryngectomy (10 out of 52 patients who received secondary tracheoesophageal puncture). ${ }^{16}$ Bozec et al. performed pharyngolaryngectomy on 37 of 103 patients studied, though not all of these received a tracheoesophageal puncture. ${ }^{11}$ These studies found secondary tracheoesophageal puncture to be significantly associated with pharyngolaryngectomy.

The effect of chemoradiotherapy, reconstruction and neck dissection was not well studied in the articles included. Five studies made mention of all of these factors, and only four of these specified the prevalence of these factors in primary and secondary tracheoesophageal puncture groups. We were unable to control for the effects of these confounding factors, which impairs our ability to study the true impact of timing of puncture.

The trend of our meta-analysis supports a non-inferior voice outcome with primary puncture, and this is reflected in the literature. Chone et al. concluded that voice success rate was significantly higher with primary puncture. ${ }^{4}$ Gitomer and colleagues concluded that fluency and voice success were similar after primary and secondary puncture, after a mean follow

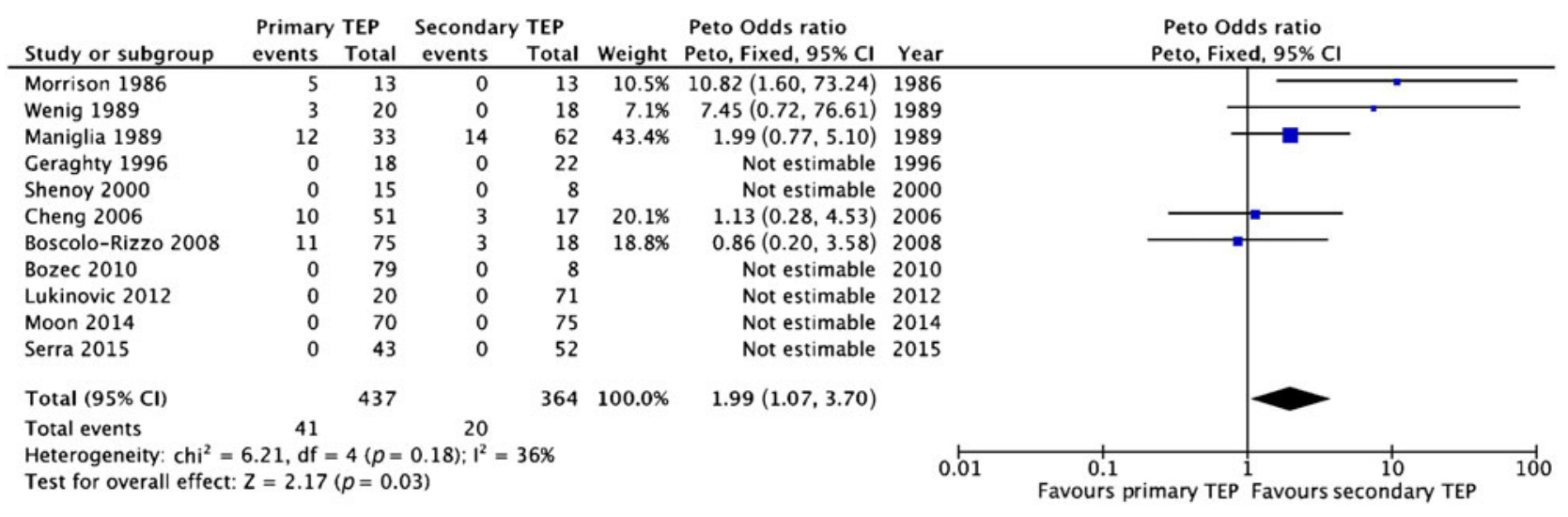

FIG. 4

Forest plot showing meta-analysis of pharyngocutaneous fistula rates after primary and secondary puncture. It appears to be significantly more prevalent after primary puncture. TEP = tracheoesophageal puncture; $\mathrm{CI}=$ confidence interval 




up of 4.7 years. $^{22}$ Sinclair and colleagues reported a median time to voice following primary puncture of 56 days versus 200 days for patients who underwent secondary puncture. ${ }^{23}$ They also found no difference in overall surgical complication rate, which was consistent throughout every paper in the meta-analysis, and was the overall trend.

As pharyngocutaneous fistula is the most serious common complication after laryngectomy, its rates and risk factors have been extensively studied. Our findings suggest an increased risk with primary puncture. This finding is supported by Emerick and colleagues' study, which concluded an increased risk of fistula in salvage laryngectomy. Conversely, studies by Dowthwaite et al. ${ }^{24}$ and Parikh et al. ${ }^{25}$ found that timing of puncture had no effect on pharyngocutaneous fistula rate. A recent large meta-analysis found that this risk is most marked with combined chemoradiotherapy over simply radiotherapy. ${ }^{20}$

Future work should focus on exploring risk factors for failing to use a voice prosthesis, as long-term success rates have now been established in both primary and secondary puncture. More emphasis should also be placed on improving the outcomes of salvage laryngectomy given the increasing prevalence of primary chemoradiotherapy treatment for head and neck cancers.

On the basis of this systematic review and meta-analysis, and the supporting literature, there are two main conclusions to be drawn. The non-inferiority of voice outcomes with primary puncture, combined with improved time to voice and no increase in overall complication rate, leads us to advocate the use of primary tracheoesophageal puncture as a safe and efficient method of voice rehabilitation. However, the increased risk of pharyngocutaneous fistula after primary tracheoesophageal puncture found on meta-analysis, albeit based on a small sample size, is supported in the literature, particularly after chemoradiotherapy.

It is our recommendation that the benefits of a primary puncture should be balanced against the risk of pharyngocutaneous fistula. Undertaking a second intervention is prudent following chemoradiotherapy, and should be considered in patients with other risk factors for fistula formation, which include anaemia, chronic obstructive pulmonary disease and concurrent neck dissection, among others. ${ }^{26}$

References

1 Singer MI, Blom ED. An endoscopic technique for restoration of voice after total laryngectomy. Ann Otol Rhinol Laryngol 1980; 89:529-33

2 Roxburgh J, Perry A. Use of a "hands-free" tracheostoma valve in patients with laryngectomy and tracheoesophageal puncture. Ann Otol Rhinol Laryngol 2004;113:565-70

3 Emerick KS, Tomycz L, Bradford CR, Lyden TH, Chepeha DB, Wolf GT et al. Primary versus secondary tracheoesophageal puncture in salvage total laryngectomy following chemoradiation. Otolaryngol Head Neck Surg 2009;140:386-90

4 Chone CT, Gripp FM, Spina AL, Crespo AN. Primary versus secondary tracheoesophageal puncture for speech rehabilitation 
in total laryngectomy: long-term results with indwelling voice prosthesis. Otolaryngol Head Neck Surg 2005;133:89-93

5 Kao WW, Mohr RM, Kimmel CA, Getch C, Silverman C. The outcome and techniques of primary and secondary tracheoesophageal puncture. Arch Otolaryngol Head Neck Surg 1994; 120:301-7

6 Cocuzza S, Bonfiglio M, Grillo C, Maiolino L, Malaguarnera $\mathrm{M}$, Martines $\mathrm{F}$ et al. Post laryngectomy speech rehabilitation outcome in elderly patients. Eur Arch Otorhinolaryngol 2013; 270: $1879-84$

7 Downs SH, Black N. The feasibility of creating a checklist for the assessment of the methodological quality both of randomised and non-randomised studies of health care interventions. J Epidemiol Community Health 1998;52:377-84

8 Maniglia AJ, Lundy DS, Casiano RC, Swim SC. Speech restoration and complications of primary versus secondary tracheoesophageal puncture following total laryngectomy. Laryngoscope 1989;99:489-91

9 Lukinović J, Bilić M, Raguz I, Zivković T, Kovac-Bilić L, Prgomet D. Overview of 100 patients with voice prosthesis after total laryngectomy--experience of single institution. Coll Antropol 2012;36:99-102

10 Boscolo-Rizzo P, Zanetti F, Carpené S, Da Mosto CM. Longterm results with tracheoesophageal voice prosthesis: primary versus secondary TEP. Eur Arch Otorhinolaryngol 2008;265: $73-7$

11 Bozec A, Poissonnet G, Chamorey E, Demard F, Santini J, Peyrade F et al. Results of vocal rehabilitation using tracheoesophageal voice prosthesis after total laryngectomy and their predictive factors. Eur Arch Otorhinolaryngol 2010;267:751-8

12 Cheng E, Ho M, Ganz C, Shaha A, Boyle JO, Singh B et al. Outcomes of primary and secondary tracheoesophageal puncture: a 16-year retrospective analysis. Ear Nose Throat J 2006; 85:262-7

13 Geraghty JA, Wenig BL, Smith BE, Portugal LG. Long-term follow-up of tracheoesophageal puncture results. Ann Otol Rhinol Laryngol 1996;105:501-3

14 Moon S, Raffa F, Ojo R, Landera MA, Weed DT, Sargi Z et al. Changing trends of speech outcomes after total laryngectomy in the 21 st century: a single-center study. Laryngoscope 2014;124 2508-12

15 Morrison MD, O’Grady M. Primary tracheo-esophageal puncture voice restoration with laryngectomy. J Otolaryngol 1986; 15:69-73

16 Serra A, Di Mauro P, Spataro D, Maiolino L, Cocuzza S. Postlaryngectomy voice rehabilitation with voice prosthesis: 15 years experience of the ENT Clinic of University of Catania. Retrospective data analysis and literature review. Acta Otorhinolaryngol Ital 2015;35:412-19
17 Shenoy AM, Ashok H, Premalata BS, Prasad AV, Nanjundappa K, Kumar S. Surgical speech restoration by tracheo-oesophageal puncture--Kidwai experience. Indian J Cancer 2000;37:27-31

18 Wenig BL, Mullooly V, Levy J, Abramson AL. Voice restoration following laryngectomy: the role of primary versus secondary tracheoesophageal puncture. Ann Otol Rhinol Laryngol 1989;98:70-3

19 Centre for Evidence-Based Medicine. OCEBM Levels of Evidence. In: http://www.cebm.net/index.aspx?o=5653 [6 November 2017]

20 Sayles M, Grant DG. Preventing pharyngo-cutaneous fistula in total laryngectomy: a systematic review and meta-analysis. Laryngoscope 2014;124:1150-63

21 Rentschler GJ, Mann MB. The effects of glossectomy on intelligibility of speech and oral perceptual discrimination. J Oral Surg 1980;38:348-54

22 Gitomer SA, Hutcheson KA, Christianson BL, Samuelson MB, Barringer DA, Roberts DB et al. Influence of timing, radiation, and reconstruction on complications and speech outcomes with tracheoesophageal puncture. Head Neck 2016;38:1765-71

23 Sinclair CF, Rosenthal EL, McColloch NL, Magnuson JS, Desmond RA, Peters GE et al. Primary versus delayed tracheoesophageal puncture for laryngopharyngectomy with free flap reconstruction. Laryngoscope 2011;121:1436-40

24 Dowthwaite SA, Penhearow J, Szeto C, Nichols A, Franklin J, Fung $\mathrm{K}$ et al. Postlaryngectomy pharyngocutaneous fistula: determining the risk of preoperative tracheostomy and primary tracheoesophageal puncture. J Otolaryngol Head Neck Surg 2012;41:169-75

25 Parikh SR, Irish JC, Curran AJ, Gullane PJ, Brown DH, Rotstein LE. Pharyngocutaneous fistulae in laryngectomy patients: the Toronto Hospital experience. J Otolaryngol 1998;27:136-40

26 Dedivitis RA, Aires FT, Cernea CR, Brandão LG. Pharyngocutaneous fistula after total laryngectomy: systematic review of risk factors. Head Neck 2015;37:1691-7

Address for correspondence:

Dr Patrick Daragh Chakravarty,

Department of Otolaryngology, Head and Neck Surgery, Ward 11B, Queen Elizabeth University Hospital

Glasgow G51 4TF, Scotland, UK

E-mail: p.d.chakravarty.08@aberdeen.ac.uk

Dr P D Chakravarty takes responsibility for the integrity of the content of the paper

Competing interests: None declared 